Woodman, D. (forthcoming) Continuity and Change in Attitudes to Job Security Across Two

Generations... Labour and Industry (author's post-review copy)

\title{
Continuity and Change in Attitudes to Job Security Across Two Generations of Young Australian Adults
}

\begin{abstract}
Responses to the rise of insecure work are complicated by claims that emerging generations place less importance on security of employment, preferring 'flexibility'. This paper investigates attitudes towards job security among young adults in Australia using survey and semi-structured interview data from the Life Patterns Study, a mixed-methods longitudinal study of two cohorts of Australian young adults (finishing school 15 years apart, in 1991 and 2006). Analysis shows that, contrary to the stereotype, job security was rated as the most important factor in deciding on a job by both cohorts. Moreover, although they also said they value flexibility, the school leaving cohort of 2006 put greater importance on job security as a factor in deciding on a job, both early in and at the end of their 20s. However, the qualitative interview data suggest that caution is needed in interpreting continuity and change in the importance of job security relative to flexibility, as there was evidence of a generational shift in the way the 2006 cohort were conceptualising employment security.
\end{abstract}

Keywords: employment conditions [security, flexibility]; generations [Generation X, Generation Y (the Millennials)]; youth; social change; mixed-methods longitudinal research.

Dan Woodman, University of Melbourne

dan.woodman@unimelb.edu.au

\section{Introduction}

Across advanced capitalist countries many young adults are spending their twenties in insecure employment, negotiating complex and unpredictable patterns of work (Chauvel and Schröder 2014). This is clearly the case in Australia, which has among the highest rates of use of insecure contracts in the OECD, with 25 per cent of employees, and 41 per cent of younger employees aged 20-24, categorised as 'casual' (on the basis that they lack entitlements associated with permanent positions such as annual and sick leave) (Gilfillan 2018). 
Woodman, D. (forthcoming) Continuity and Change in Attitudes to Job Security Across Two

Generations... Labour and Industry (author's post-review copy)

Understanding these changes and advocating for a policy response is complicated by claims that the emerging generation has different employment priorities to those before. There is an ever growing academic and popular literature on generational differences in the workplace and attitudes to work (Johnson and Johnson 2010, Twenge et al. 2010, Costanza et al. 2012, Lyons and Kuron 2014, Stewart et al. 2017). Some portray the generations as radically different from each other in their self-confidence, attitudes towards security and flexibility and the way they prioritise intrinsic and extrinsic rewards. As such, the claim is often that new expertise is needed if generations are to be able to work together and for employers to be able to successfully hire, retain and manage the 'Millennials' (Lyons and Kuron 2014). There are also critics, with some questioning the existence of meaningful generational differences at all (Costanza et al. 2012).

This paper contributes new evidence to these debates, drawing on a longitudinal mixed-methods study tracking the experiences of the two cohorts of Australians from their late teens through to their mid-forties for the first cohort (school leaving cohort of 1991) and through to 30 (ongoing) for the second (school leaving cohort of 2006). The participants have been asked in survey questions what they value in a job and in interviews about their views and experiences of employment. This allows a qualitative and quantitative comparison at the same age of attitudes to work across two cohorts that finished school fifteen years apart. The data from this study show that secure work is the most important aspect of employment for these young adults in their early twenties and at thirty, as it was for the generation before. Yet, the interviews suggest that this is not straightforward evidence against generational differences, as the meaning of job security appears to be being redefined.

\section{Researching Generational Change and Attitudes to Work: Context and Approaches}

This section provides background context for the study, outlining prevailing assumptions and recent research on generational change in attitudes to work. The need for a new approach based on the sociology of generations is advocated.

\section{Popular Stereotypes and the Need for Labour Market Context}

The then Chief Executive Officer of Myers, Australia's largest department store1, claimed in an address to The Australian Financial Review Workforce and Productivity Summit in 2015 that young people 'really want to work in a way that suits their lifestyle and they think in terms of work-life balance and that isn't something typically that's enhanced by a restrictive regime'. He 
Woodman, D. (forthcoming) Continuity and Change in Attitudes to Job Security Across Two

Generations... Labour and Industry (author's post-review copy)

argued that 'Millennial' workers 'crave flexibility and in many ways their interests are aligned, between employers and future employee'. While this is obviously self-interested, the claim received no scrutiny when it was made, fitting with broader understandings about this generation, as overly confident and focused on the short-term (Twenge 2014).

Young people are finishing education, entering full-time 'career' work, making household transitions and having children at a later age (Buchmann and Kriesi 2011). This is sometimes portrayed positively, as young people being allowed to 'move into adulthood responsibilities gradually, at their own pace' (Arnett 2014:8); sometimes negatively, as a generational cohort expecting too much while wanting to avoid responsibility (Twenge 2014). Either way, these changes are presented as a new generational attitude.

However, any claims of attitude change can only be understood in the context of young adults having faced some of the greatest negative effects of economic change (Chauvel and Schröder 2014, Cote 2017, Farthing 2017). The labour market has been reshaped by the disappearance of many entry level jobs and the emergence in their place of jobs with poor employment conditions; young people often need a degree qualification and five years or more experience to be competitive for the jobs offering 'standard' conditions (Price et al. 2011).

\section{Academic Research into Generational Change in Attitudes Towards Work}

There is now a significant amount of academic research into inter-generational differences in attitudes towards work. The cohorts labelled the 'Millennials' or 'Gen Y' (born from the early 1980s to around 2000) are portrayed as less committed, more focused on flexibility but concurrently with greater pay and promotion expectations than previous cohorts (Twenge et al. 2010, Costanza et al. 2012, Krahn and Galambos 2014). There is also a critical literature arguing that age, psychological and other differences dwarf any minor generational effects (Giancola 2006, Benson and Brown 2011).

Arguably the most influential study of generational differences in attitudes towards work is Twenge and colleagues' (2010) analysis of surveys of high-school graduating classes in the USA from 1976, 1991 and 2006. They show that extrinsic values (a job that has high status, a role that people look up to and respect, high earnings) and leisure values (a job that leaves a lot of time for other things, that is mostly free of supervision, and has an 'easy pace') increased in importance relative to intrinsic values (a meaningful, interesting job that uses and develops skills) over time. 
Woodman, D. (forthcoming) Continuity and Change in Attitudes to Job Security Across Two

Generations... Labour and Industry (author's post-review copy)

Twenge uses analysis of this data to present an unflattering portrait of the 'Millennials' as selfcentered, even 'narcissistic'; a generation expecting high pay and respect with little responsibility and short hours, paradoxically experiencing poor mental health when the world fails to match their unrealistic expectations (Twenge 2014).

Krahn and Galambos (2014) add a panel longitudinal design missing from other studies, comparing Canadian high-school graduating classes of 1985 and 1996 surveyed twice, aged 18 and 25 (framing them as part of 'Gen X' and 'Gen Y' respectively, although the 1996 group would fall at the end of 'Gen $X$ ' in most typologies). They found similar levels of intrinsic motivation across the two cohorts, with these aspects becoming more important for both groups between 18 and 25. The 1996 'Gen Y' cohort also put more value on extrinsic factors as they aged, while they decreased in importance for the 1985 cohort. Krahn and Galambos (2014) showed that attitudes can strengthen or change direction over time and that the importance of intrinsic and extrinsic rewards are not directly traded off in people's evaluations. They are cautious to note the differences are not large; however, they present their findings as consistent with Twenge's (2014) overall view of 'Gen Y' as more entitled.

These academic studies of generational shifts in attitudes to work have a foundation in psychology and management, even though not all the examples given are from researchers formally located in these disciplines. A broader sociological focus that examines attitudes in the context of employment opportunities and conditions provides an important additional dimension. Particularly in the wake of the global economic crisis from 2007, within the sociology of youth there has been increasing focus on the effects of underemployment and job insecurity for younger people (Cote 2014, Cairns 2017, Ng et al. 2017). This literature, however, has not yet significantly influenced research on generational differences in attitudes to paid work: a review of this field seven years after the economic crash still found recent claims that young people put less value on security (Lyons and Kuron 2014). Even within the sociology of youth literature that does recognize these changes in the employment conditions of young people, it is common to find an untested acceptance that young people put less value on job security, but framed as a response to structural shifts that reshape young people's subjectivity in ways that encourage them to develop individualised and entrepreneurial attitudes towards all aspects of their life (Kelly 2016, Ikonen, and Nikunen 2019). 
Woodman, D. (forthcoming) Continuity and Change in Attitudes to Job Security Across Two

Generations... Labour and Industry (author's post-review copy)

While young people's attitudes towards paid work have been heavily researched, the data has not been available to ascertain more accurately the degree of change that has occurred in young people's attitudes towards security and flexibility in employment and whether these changes represent generation effects. The limitations of existing research are not just, or even primarily about the data, the conceptual framings of generations used in this research are often blunt. This points to the potential value of longitudinal and qualitative data and a fuller engagement with the sociology of generations, to provide a nuanced framework for understanding changes in attitudes towards employment security and flexibility.

\section{A Better Way to Research Generational Attitudes to Work}

The foundation for nascent generational attitudes emerges in conditions of change. An enquiry drawing on the sociology of generations marks out how understandings and attitudes have altered in the context of economic and social change, while acknowledging diversity within the emerging generation (Woodman 2016). A new generation emerges when the previous constellation of beliefs and ways of life become difficult to maintain, either because they are no longer practical or no longer valued, and a set of related alternatives develops among new cohorts. This approach demands a research design employing qualitative methods, at least in part. There is an assumption in much of the scholarship on generational differences at work that the meaning of the various rewards of work remains constant over time for new cohorts. This is particularly methodologically suspect in the context of making claims about generations, where attention to changing meanings should be central. Without qualitative research, the meaning of aspects of work that scholars claim is becoming more important is defined by the researcher.

The view that the 'Millennials' value flexibility in place of security remains powerful and has political dimensions. However, it needs to be more rigorously tested empirically, both in terms of quantitatively identifying change over time and qualitatively investigating changes in meaning. This article contributes to these goals, drawing on a rare two-cohort mixed-methods longitudinal design to apply a sociological frame to the question of the role of security in what a group of contemporary young people want from work and whether this is different from the previous generation.

\section{Research Design and Data}


Woodman, D. (forthcoming) Continuity and Change in Attitudes to Job Security Across Two

Generations... Labour and Industry (author's post-review copy)

I draw here on a design similar to that used by Krahn and Galambos (2014) with the added advantage of qualitative interview data. Krahn and Galambos (2014) utilised a multi-cohort longitudinal study design, noting that there were no comparable results at that time using this powerful method. Their design overcame the limitations of Twenge and colleagues' (2010) study, which used repeated cross-sectional measures from multiple cohorts, and which - in the absence of longitudinal data - was unable to address whether observed cohort differences were transient.

This analysis draws upon the Life Patterns longitudinal research program. Life Patterns has followed the young adulthoods of two cohorts of Australians, the first are members of 'Generation $\mathrm{X}$ ' and the second of 'Generation Y' (or 'Millennials') in the popular terminology2. The '1991 cohort' has been followed since they completed secondary education in that year. The '2006 cohort' finished secondary education in that year and have also been followed since that time. The research program has the broad aim of tracing educational, work, and other social transitions.

The study employs a mixed-method approach, using questionnaire surveys (initially posted, then more recently distributed to participants as online questionnaires) and in-depth interviews with a subset of participants. This design allows a comparison between the two cohorts at the same age. Such designs are rare due to time and cost, but arguably represent the ideal for research questions about generational change (Twenge et al. 2010), particularly when quantitative data is paired with interview data. It is the only longitudinal study of Australia youth to trace transitions through to participants' 30s and to have more than one cohort.

\section{The sample}

The 1991 cohort sample was derived from a government school-exit survey for 29,155 school leavers in Victoria. A representative sample of 2,000 participants was selected from this group. From 1996 to the year 2000 annual surveys and individual in-depth interviews with a sub-sample of between 50 to 100 respondents were conducted. From the year 2000, surveys were conducted bi-annually and participants were only interviewed occasionally for particular sub-projects. The 2006 cohort was recruited through the end of 2005 and into 2006, using a stratified (by sector) random-sampling of secondary schools in Victoria, NSW, ACT and Tasmania. All students in the selected schools expected to complete school in 2006 were invited to participate. A total of 3977 completed the initial questionnaire during school time, with 2100 completing the first wave of the 
Woodman, D. (forthcoming) Continuity and Change in Attitudes to Job Security Across Two

Generations... Labour and Industry (author's post-review copy)

longitudinal survey in 2007. The 2006 cohort has been surveyed annually, and a sub-set (30-55) has been interviewed most but not every year.

As is common with longitudinal surveys of youth, attrition is a limitation. The 2006 cohort at age 30 had 508 participants and at the same point the 1991 cohort had 625 participants. Another limitation of the sample is the different recruitment methods for the two cohorts. However, statebased differences are minor across the 2006 cohort sample and the two cohorts are very similar on demographic dimensions. There has been greater attrition of men than women for both cohorts, which is again a common pattern in such studies of youth. The sample for both cohorts has otherwise retained consistency in terms of location and socioeconomic background. In the 2006 cohort, 68 per cent are women and 32 per cent are men; in the 1991 cohort 67 per cent are women and 33 per cent men (at age 30). Among 1991 cohort participants, 85 per cent has completed a tertiary level qualification, as has 77 per cent of the 2006 cohort (with some of this cohort still in study). This percentage of graduates is higher than the wider Australian population. Interview participants, a subsample of both cohorts, were recruited for a representative gender split, and a mix of metropolitan/ non-metropolitan and socio-economic backgrounds.

\section{Data and analytical approach}

In this paper I use qualitative and quantitative data from both cohorts, with the qualitative data carrying the larger analytical burden. The quantitative analysis is based on survey questionnaires which contained closed questions of various types, often using a Likert-type response (with some open-ended responses). The qualitative analysis is based on text from semi-structured and openended interviews, asking about experiences of education, work, relationships and mental health.

The quantitative results are reported first in a descriptive analysis focused on answers to a repeated survey question about important factors in deciding on a job, comparing the cohorts at the same age at two points (aged 23 and 30). The dataset used includes only participants in employment who answered this question at age 30 and at age 23, giving 544 participants in the 1991 cohort, and 420 participants in the 2006 cohort. These data provide a basis for the qualitative analysis in which I use interview excerpts from questions about employment (their experience of paid work, the contract status of the work, how work impacts on other spheres of life), coded for commonalities. Interview data for the 1991 cohort comes from interviews conducted in 1999 (into 
Woodman, D. (forthcoming) Continuity and Change in Attitudes to Job Security Across Two

Generations... Labour and Industry (author's post-review copy)

2000), when the participants were 8-9 years post school (100 interviews) and cohort 2 from 2015

(50 interviews) when participants were 9 years post-school. 3

The Importance of Job Security in Employment: Comparison Across Two Cohorts

As outlined above, the results of my analysis are reported in two sections. The first presents descriptive statistics from surveys of the two cohorts, the second elaborates on the statistical picture through analysis of interview data.

\section{Quantitative rankings of job security relative to flexibility}

In this section I report responses to a survey question on what job characteristics participants valued most highly when making a decision about work. The central focus is the relative ranking of security and flexibility. Figure 1 shows the responses from the two cohorts (aged 23 and 30) on these and a range of other job characteristics. 
Woodman, D. (forthcoming) Continuity and Change in Attitudes to Job Security Across Two

Generations... Labour and Industry (author's post-review copy)

Figure 1: Importance of security and related job characteristics at age 23 and 30, 1991 cohorta and 2006b cohort (percentages reporting 'very important'c).

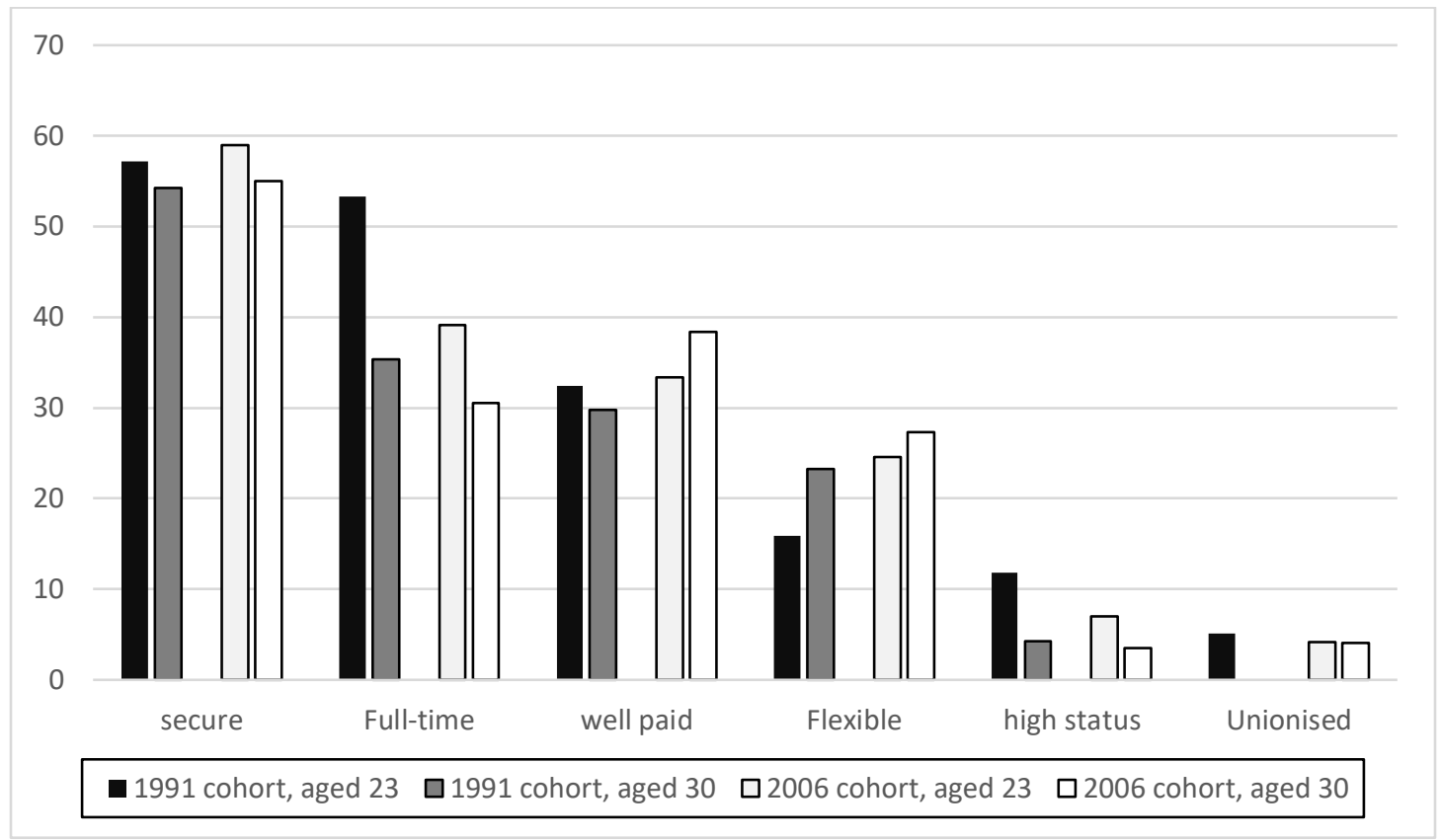

Notes

a) N 544 for 1991 cohort (data from wave 3, 1996 and 9, 2003). The union item was only asked of the 1991 cohort once.

b) N 420 for 2006 cohort (data from wave 7, 2011 and wave 14, 2018).

c) Based on a five-point scale.

Source of data: Life Patterns Study, longitudinal research program

While the 2006 cohort were, on average, somewhat more likely to want a job that is 'flexible' and less likely to rate full-time hours as very important, for both cohorts, security was clearly ranked as the most important feature for deciding on a job. At age 23, 57 per cent of the 1991 cohort and 59 per cent of the 2006 cohort ranked a secure job as 'very important'. Security, counterintuitively, became slightly less important over time, decreasing by about 3-4 percentage points from age 23 to 30 (for both cohorts), plausibly related to people shifting into ongoing contracts or other roles that meant it became at least partially taken for granted. However, security was always the most highly ranked item by a clear margin across all waves for both cohorts.

For both cohorts, flexibility was ranked below pay and full-time employment but became more important as the participants aged. Again, this goes against the stereotype that it is younger people 
Woodman, D. (forthcoming) Continuity and Change in Attitudes to Job Security Across Two

Generations... Labour and Industry (author's post-review copy)

who most want flexibility, but it makes sense when we consider that by age 30 people are often combining demanding roles that have limited flexibility with caring obligations. Full-time employment also became less important (as some became parents), as did the status of the work, which was ranked lowly at age 23 and became even less important by age 30 . While unionisation may contribute to security in practice, it was not ranked highly by respondents from either cohort - perhaps unsurprisingly given the wider context of deunionisation. It was only on pay where the values of the two cohorts did not follow a similar pattern as they aged, with high pay becoming more important for the 2006 cohort and less important for the 1991 cohort between ages 23-30 (plausibly linked to the housing boom that occurred in Australia's major cities during this period of their life for the second cohort).

Intriguingly, much of the previous research into generational attitudes towards work does not directly measure attitudes to job security and claims about attitudes and generational patterns concerning security tend to be based on assumptions (including in the most influential studies, such as Twenge et. al 2010). The results presented here are direct measures of attitudes towards security and show that for these participants cohort differences in attitudes were small in relation to job security and went in the opposite direction to predictions based on generational stereotypes, with the 2006 cohort ranking security slightly more highly than the 1991 cohort in both age groups. Fitting more closely with existing generational typologies, flexibility was rated more highly by the 2006 cohort (particularly at age 23) although the overall pattern among the items was similar across cohorts. The higher importance given to flexibility by the 2006 cohort could be interpreted as evidence that these participants did not think of the two qualities (security and flexibility) as incompatible. The qualitative data below gives some insight, however, into the complexity of the relationship between the two.

\section{Qualitative shifts in the meaning of job security relative to flexibility}

In this section I draw on qualitative interview data from the two cohorts at the approximately the same age (26) to examine whether generational differences may be more visible on a different register - that is, shifts in the way participants conceptualise employment security and flexibility.

1996 Cohort 
Woodman, D. (forthcoming) Continuity and Change in Attitudes to Job Security Across Two

Generations... Labour and Industry (author's post-review copy)

When interviewed in 1999 in their mid-20s (age 25-26), members of the 1991 cohort were still finding their way in the job market, as Australia was still recovering from the 1990-91 recession. They had invested significantly in their education, following exhortation from the government and the previous generation to do so, in the context of the economic downturn (Dwyer et al. 2001). 'I always thought the only way for me to get a good job was to work hard at school and get a certificate in something' (Dan).4 Few believed that they would get a decent job without qualifications, sensing that this possibility - which was largely realistic, particularly for young men, during the youth of the Baby Boomer cohorts - had been closed off by the recession and labour market change.

Yet, they were surprised to find that even a further qualification was not enough to find job security. Several participants expressed disappointments about the challenges they faced in converting their educational qualifications into the secure employment outcomes they were expecting.

I thought once I had a degree it would all fall into place. Job security just isn't there. (Logan)

I have a certificate and now they want work experience, I can't win. (Sally)

I did the course straight through... and now I'm finished I can't get a job because I have no practical work experience in the area. There are thousands of people with marketing degrees and none of us can get work. (Pam)

This sometimes turned to anger - at employers, the government, parents and educational institutions - for broken promises. Shari no longer believed the 'promises' from her employer:

Unfortunately, despite all the promises there was no new contract when the last one ran out, so I have had to take on work I have no experience or qualifications in, working for a bunch of cowboys who would sack me in a minute if I spoke up about anything.

Others noted a loss of faith in the educational institutions and parents who had led them to believe education was a passport to job success 'I trusted them when they told me that a ticket would open doors for me' (Stuart).

Participants mentioned very similar reasons why job security mattered for planning ahead: 
Woodman, D. (forthcoming) Continuity and Change in Attitudes to Job Security Across Two

Generations... Labour and Industry (author's post-review copy)

It is not exactly skilled work and there is no security in it, which makes it hard to make plans. It's hard to know where you will be six months down the line when you don't know whether you will have a job or not. (Dale)

It makes it hard to plan where you're going to be six months down the line when you don't even know if you'll have a job (Mark).

However, among some participants there was an individualised narrative emerging that personal attributes were what made people stand out among the growing number of others with qualifications. 'Everything has been down to me! I set my own goals and when things have to be reassessed, I will do that' (Gary).

Yet, even those who believed in the power of individual effort saw investing too much of selfidentity in employment as risky. 'There is no one priority in my life.... my family, my part-time work are all important.... you only get disappointed [if have a single priority]' (Moira); it was important to 'work to live, not the other way around - quality outside hours' (Shaun). Similarly, Fiona, who worked as a furniture designer, spoke about changing her approach to work:

I am trying to deal with problems when they occur rather than worry about them....I am trying to change my philosophy from 'live to work' to 'work to live'.

Overall the 1991 participants (part of 'Generation X') largely followed the directions given to them by the generation before. They participated in further education in large numbers and worked hard to find a secure job. They had started their twenties with expectations about paid work in line with a feeling of having done what was asked of them, particularly investing in education. By their midtwenties, however, the idea that employment could be relied on in this way had been profoundly tested; work/life balance, not investing too much of their sense of self in a particular job, and backup plans emerged as key concerns of the group (see also, Dwyer et al 2000, Wyn and Woodman, 2007). The interviews with the second cohort which I turn to in the following section, suggest that, although they still valued security at work very highly, they did not seem to be responding to insecurity in the same way. This related to how they thought about 'flexibility'. It also meant they did not go through the same level of disillusionment as members of the 1991 cohort they progressed through their $20 \mathrm{~s}$.

2006 Cohort 
Woodman, D. (forthcoming) Continuity and Change in Attitudes to Job Security Across Two

Generations... Labour and Industry (author's post-review copy)

The 2006 cohort was interviewed in 2015 (aged 26-27). While not experiencing a recession like the 1991 cohort, this group experienced the financial crisis and its aftermath just after finishing high-school. Although casual and short-term contracts have not increased or decreased markedly between cohorts, they have become entrenched and, for the 2006 cohort relative to the 1991 cohort, more time had passed since the relatively smooth employment trajectories of the Baby Boomers.

For the 2006 cohort, not even the public service provided a guarantee of a permanent contract. Adrian had pursued a job in the public service, in part because he felt it would be more secure. However, this was not the case:

It's not just here, it's all of the Australian Public Service [that] has a hiring freeze. Until that's lifted, they can't hire any permanent employees. Probably 30 per cent of us are nonongoing. It's a lot of stress....It does have an unintended good side, which is that you work really hard because you want to show that if they can only renew five out of ten contracts that you want to be one of the five.

The 2006 cohort participants (like those in the 1991 cohort) were keen on a job that offered security, explaining that this was important for limiting stress:

It's just that [with] security in employment, they'd have to let me know if they were making me redundant.... The good thing about permanent work is that it reduces your stress level knowing that you have a reasonably secure job....It's not like when you're a casual and they could let you go anytime that suited them. (Leah)

The 2006 participants thus echoed the sentiments of the earlier cohort in terms of valuing security in employment, and not finding it readily available. There were, however, some differences in the way the 2006 cohort interview participants were conceptualising job security, relative to the 1991 cohort interviewees.

Redefining the Meaning of Security Interviews suggested that some participants in the 2006 cohort were redefining security in a way tangential to their contract type. Dylan, who was a professional coach of junior basketball, put it like this:

Interviewer: Do you think of your work as ongoing or permanent?

Participant: Yeah, I like to think it will be. They want consistency from coaches for the sake of the kids because they want someone who is going to stay with those kids for as 
Woodman, D. (forthcoming) Continuity and Change in Attitudes to Job Security Across Two

Generations... Labour and Industry (author's post-review copy)

long as they can....just because that's what they value. It's not in a contract or anything...It's casual. It's not any time period or anything. Yeah, so I mean it's ongoing at their discretion.

There was some evidence of this type of attitude in the 1991 cohort interviews, but it had notably intensified in interview transcripts from the 2006 cohort. A clearly new element in the 2006 cohort interviews was that some saw accepting an offer of a contract that increased job security as implying the demand of a reciprocal long-term commitment to that employer. If they could not or did not want to stay at an employer for the longer-term, some were hence hesitant about taking a permanent contract, hoping instead that their personal value to the employer would give them a degree of security.

No, there's no way [I'd go on a permanent contract]. [Laughs] That's horrible to say. I do love my job, but I don't see it as a forever profession. I think you'd go crazy to tell you the truth.....Yeah, look I do feel secure because I do know that the leaders recognise that I work hard. So, I don't think I'm too worried about losing my job. (Sara)

I have gotten to a point where I'm just like, I don't need a contract. Like, I definitely still get anxious, but I think I'm more optimistic about it than maybe I should be, sometimes [because contract keeps getting renewed]..... My parents definitely wouldn't say I'm permanent... If they offered me full time now, or permanent, I would probably not take it...just because I'd be quitting at the end of like two, the next contract or two. I feel as though, generally, if you take a full-time contract to that company you're expected to stay there for quite a while after that and I do not want to do that. But definitely, I think, the stability of that in the future would be great (Nick).

While many in the 1991 cohort felt angry that the jobs they had hoped for, particularly secure jobs, were not available, the 2006 interviewees instead seemed to be redefining security, and relatedly the role of education. Carla, working in journalism, a field with an uncertain future, somewhat creatively defined herself as relatively secure at work, but saw this as involving tradeoffs:

I think my position is quite secure. I'm one of like a new generation of journalists that can do all of the digital things and edit videos and do sort of every aspect of journalism and I'm on a low wage still. So I have a lot of skills and I'm cheap so I think I'm a lot safer than 
Woodman, D. (forthcoming) Continuity and Change in Attitudes to Job Security Across Two

Generations... Labour and Industry (author's post-review copy)

some of the older journalists .... I definitely couldn't afford a house on the wage that I'm on.... That's why I'm back at uni[versity] because one day I will have to earn more money than probably what journalism can offer.

Flexibility v Security: Changing Perspectives on Work-Life Balance In the previous section I presented excerpts suggesting that the 1991 cohort had stressed the importance of work/life balance as a partial remedy to employment insecurity, emphasising the importance of life outside of employment because they did not feel they could be too invested in insecure paid employment (see also, Dwyer et al. 2001; Wyn and Woodman 2006, 2007). While the Boomers were the generation who first embraced 'work-life balance' as a value, they did this as they aged, after establishing themselves in workplace hierarchies or as they moved into dual employment and care roles. We interpreted our 1991 cohort's focus on balance, from an early age, differently; it was partly a focus on individual development outside of work but also an effort to escape the continual demands to succeed in a fickle and precarious labour market that no longer provided the foundations for a meaningful locus of identity (Wyn and Woodman 2007). The second cohort appeared to be taking a different path again, blurring the boundaries between work and life and reinterpreting security in individualised terms, which nonetheless still calls for the activity of balancing competing demands, albeit no longer easily partitioned into 'work' or 'life'.

The interview participants from the 2006 cohort tended to talk differently about balance. Many were juggling more than one work commitment concurrently, sometimes with education. Bessie was working three jobs: as an arts administrator, primary school teacher and private music teacher.

I'm short term temporary contract at the moment [in my teaching]... I'm just filling in for someone who's on sick leave, but it's sounding like there's treatment involved in that sick leave, so it's expected to be extended probably. But other than that it's casual relief, so you're on no commitment. My private students, there's no contract there. That's just selfemployed.... It's a permanent position that one [the arts sector job]. But I mean it's insecure in that it's arts, so when money goes, positions [go]. I do ultimately [want a more secure job], yes, but probably in this year it suits me to - as long as financially we can manage it suits me to have the flexibility.... It would not suit me if my partner didn't have financial stability. That would be very nerve-wracking, so if I was independent, if I was on my own, I wouldn't like it. 
Woodman, D. (forthcoming) Continuity and Change in Attitudes to Job Security Across Two

Generations... Labour and Industry (author's post-review copy)

Carla, the journalist quoted earlier, in another part of her interview turned to work-life balance.

My hours at work are my hours, class is class, you've got to go. You've got to turn in the assignments that are required. So now that I'm embarked on this path there is not really anything that I can do to rework the balance. All my friends who are young journalists, like me, have trouble with balance as well and they're very busy and are stretched but so are my friends who are young lawyers and architects and doctors and nurses and all sorts. Everyone is really, really overworking themselves to try and, I guess, get a foot in the door with their industry.

While there was a pervasive sense of work being precarious, for this cohort balance had taken on a new meaning closer to juggling of demands and resilience (sometimes relying on or supporting a partner/other family), being able to continue with 'trying to get a foot in the door' even when things were challenging and to find time to fit in leisure, time with friends and other responsibilities around work. In general, the participants did not express the same anger as some in the 1991 cohort did about their paid work and there were no examples of participants withdrawing from investing their identities in the world of work as a form of protection (a number, like Carla, went back to study for a second further qualification, while working).

A sense of security in employment, which as has been shown was highly valued by these participants across both cohorts, was particularly for the 2006 cohort often built through an attitude of working on the self. This suggests that researchers should be cautious in moving from a focus on extrinsic rewards among young people as a sign of narcissistic entitlement (Twenge et al, 2010; Twenge 2014). In this world of blurred boundaries, the distinction between extrinsic, intrinsic and even 'leisure' work rewards start to break down. A sense of 'entitlement' might be partly a myth imposed onto 'Millennials', by those who could previously take for granted many of the things they accuse young cohorts of unrealistically expecting or hoping for (Krahn and Galambos 2014, Carins 2017). Members of our 2006 cohort are responding to changed labour-market conditions in a way that may be better conceptualised as a generational shift in how security is imagined (though not its importance) in the context of the normalisation of insecure contract types, not as a generational shift toward narcissism and a demand for flexibility instead of security.

Steve, a young man working as a paralegal after doing an undergraduate degree provided a particularly clear articulation of this common attitude among the 2006 cohort: 
Woodman, D. (forthcoming) Continuity and Change in Attitudes to Job Security Across Two

Generations... Labour and Industry (author's post-review copy)

It's good to have goals because it keeps you from going off track, but nothing in the future is truly certain. I've learned not to stress too much about the next five to ten years, because [the work environment] is constantly changing. As for my career goals at this stage of my life, my focus isn't about reaching a specific role or position, but rather, to learn and to evolve myself as much as possible. For me, it's about having a strong set of employable skills and remaining flexible enough to adapt to the changing environment. This way, when the right moment or right role arises. I'll be ready to capture it.

Understanding generations from a sociological perspective can help frame understanding of young people's responses to the embedding of less secure contract types (Woodman and Wyn 2015, Farthing et al. 2017) and the rise of the 'self as enterprise' (Kelly 2016). The attitude expressed in the above excerpts is similar to that captured by the concept proposed by Kelly (2016) of 'self as enterprise', if it is recognised that 'entrepreneurialism' is a euphemism for a circus performer like attitude towards work and life (juggling, tightrope walking). For such a performer, flexibility cannot be defined in opposition to security. Participants from the 2006 cohort want job security and highlight the same effects of insecurity as the 1991 cohort. Yet they are thinking about security in a different way that could paradoxically mean that at least some were reticent to say they wanted an ongoing contract when they could not or did not want to commit to that particular job for the longer term. Some, like Nick and Sara, do not feel that they can expect an ongoing contract, if they hope to move on to other work, even if only in the medium term (a couple of years). For some of these participants a sense of security was instead connected to a narrative of moving, developing new skills and being ready to capture the right moment.

\section{Discussion and Conclusion}

In the popular press and some academic accounts, the concept of generations is used simplistically, furthering stale stereotypes - 'narcissistic Millennials', 'selfish Baby Boomers', 'cynical Gen Xers'. Even academic work can fall into this trap, conflating age effects with generational effects and overinterpret small cohort differences, while at the same time unable to see real generational changes because of not accounting for changes in the meaning of questionnaire items over time. While there are shifts between cohorts in average attitudes towards work, family and political questions, these are often small. They get warped into a narrative of generational defining oppositions when we are divided and united in many other ways (including gender, race and class). 
Woodman, D. (forthcoming) Continuity and Change in Attitudes to Job Security Across Two Generations... Labour and Industry (author's post-review copy)

However, a sociological definition of generations focuses on the possibilities of a cohort creating new way of doing things when the old ways don't work anymore. A generation is not defined by a shared set of attitudes and values that are the opposite to the previous generation, but the appearance of new attitudes and social divisions in emerging cohorts as the stakes change (Woodman 2016).

Generational differences at work is a mainstream area of management and psychological research (Costanza et al. 2012, Lyons and Kuron 2014, Stewart et al. 2017). Yet this scholarship tends to leave untested assumptions about possible generational changes not just in the relative valuation but in the meaning of aspects of work (including flexibility and security). A sociological generational frame explicitly brings the possibly of such shifts into the centre of research. Given the scope of recent change, it likely that generational differences in attitude have arisen; young people will want to, and will no doubt have to, develop different careers to their parents. Those who completely dismiss such differences are ignoring much evidence and the implausibility of the rapid change of recent decades having no impact on dispositions (Costanza et al. 2012). Yet the evidence is not straightforward and need nuanced interpretation.

Generational changes cannot be properly traced empirically with cross-sectional or even solely quantitative comparisons.

There has been a tendency to shift from quantitative evidence about young people's work patterns to assuming this must represent at least in part what younger cohorts want and for the relationship of values to social conditions not to be interrogated in any depth. While there are limitations to the Life Patterns study and its data set, in this paper I have been able to draw on longitudinal data across two cohorts and qualitative and quantitative data to show that these young adults, from two cohorts separated by 15 years, say they value job security and that both cohorts point to similar negative effects from a lack of employment security. The qualitative research cannot give a quantitative estimate of how widespread a new generational attitude is but by making a qualitative comparison across cohorts, I am able to suggest that our 2006 cohort interview participants appear to be redefining the meaning of security and its relationship to 'flexibility' in the context of a changing world of work. 
Woodman, D. (forthcoming) Continuity and Change in Attitudes to Job Security Across Two

Generations... Labour and Industry (author's post-review copy)

There are important similarities in the attitudes of the two cohorts in this study and the differences are subtle. The 1991 cohort thought work/life balance was important in part because they didn't want to invest too heavily in insecure paid work that did not seem to be delivering the economic and identity security they had expected. The 2006 cohort have similar hopes from work and are responding to similar pressures by blurring the boundaries between work and life in a different way and in some senses investing more of themselves in their paid employment (as the boundaries between work and non-work have blurred). The 2006 participants echoed the 1991 cohort in placing an overriding value on security in employment. However, the 2006 cohort participants show signs of creatively reinterpreting security, pushed by new generational conditions.

As the future of work is debated and shaped by economic change and policy, further mixedmethods, and longitudinal, sociological research is needed to interpret generational change. Policy makers should treat cautiously any claim that the wants of young workers and the senior executive of major employers (as in the example above, the Myers department store) neatly align. It is important to note that young adults differ in sociologically significant ways. While this paper has focused on commonalities within generations, there are different resources available to different young people to manage this new world of work and to succeed in a context where security is being redefined as a personal attribute. Despite and across these differences, contemporary young people are living different lives to their parents and even the generation immediately preceding them. Yet, they share a desire for security and many other things from paid work that earlier generations wanted and many of whom could achieve.

\section{Acknowledgements}

The Life Patterns study is undertaken by a team of scholars at the University of Melbourne, led by Professor Johanna Wyn. The author is a co-Chief Investigator on the current stage of the research with Professor Wyn and Professor Helen Cahill. Two team members, Dr Jenny Chesters and Dr Eric Fu assisted with preparation of the quantitative data for analysis and created Figure 1. Other current team members are Professor Carmen Leccardi, Dr. Hernán Cuervo, Dr Mark Mallman and Dr Andres Molina. The Life Patterns study has been funded by several research grants from the ARC and other sources, most recently the Australian Research Council Discovery DP160101611. This particular analysis was supported by an individual ARC research fellowship for the author - DE160100333. 
Woodman, D. (forthcoming) Continuity and Change in Attitudes to Job Security Across Two

Generations... Labour and Industry (author's post-review copy)

\section{References}

Arnett, J (2014) Emerging Adulthood (2nd ed) New York, Oxford University Press.

Benson, J \& Brown, M (2011) 'Generations at Work: Are there Differences and do they Matter?'

The International Journal of Human Resource Management, 22(9) pp. 1843-1865.

Buchmann, MC \& Kriesi, I (2011) 'Transition to Adulthood in Europe' Annual Review of Sociology, 37(1) pp. 481 -503.

Cairns, J (2017) The Myth of the Age of Entitlement: Millennials, Austerity, and Hope, University of Toronto Press, Toronto.

Chauvel, L \& Schröder MG (2014) 'Generational Inequalities and Welfare Regimes' Social Forces, 92(4) pp.1259-1283.

Costanza, DP et al. (2012) 'Generational Differences in Work-related Attitudes: A Meta-analysis' Journal of Business and Psychology, 27(4) pp. 375-394.

Côté, J E (2014) 'Towards a New Political Economy of Youth' Journal of Youth Studies 17(4) pp. 527-543.

Dwyer, P, Harwood, A \& Tyler, D (1999) Seeking the Balance: Risks, Choices and Life Priorities in the Life-Patterns Project, 1998-1999 (Working Paper 19), Melbourne: Youth Research Centre, The University of Melbourne.

Dwyer, P, Tyler, D \& Wyn, J (2001) Journeying through the Nineties: The Life-Patterns Project 1991-2000, Melbourne: Youth Research Centre, The University of Melbourne.

Farthing, R et al. (2017) The Precarious Generation: A Political Economy of Young People, London, Routledge.

Gilfillan G (2018) Characteristics and Use of Casual Employees in Australia, Canberra, Parliamentary Library.

Giancola, F (2006) 'The Generation Gap: More Myth than Reality' Human Resource Planning, 29(4) pp. 32-37 
Woodman, D. (forthcoming) Continuity and Change in Attitudes to Job Security Across Two

Generations... Labour and Industry (author's post-review copy)

Ikonen, HM \& Nikunen, M (2019) 'Young Adults and the Tuning of the Entrepreneurial Mindset in Neoliberal Capitalism' Journal of Youth Studies, 22(6), pp.824-838.

Johnson M \& Johnson L (2010) Generations, Inc, AMACOM, New York.

Kelly, P (2016) The Self as Enterprise: Foucault and the Spirit of 21st Century Capitalism, London: Routledge.

Krahn, HJ \& Galambos, NL (2014) 'Work Values and Beliefs of "Generation X” and "Generation Y"' Journal of Youth Studies, 17(1) pp. 92-112.

Lyons, S \& Kuron L (2014) 'Generational Differences in the Workplace: A Review of the Evidence and Directions for Future Research' Journal of Organizational Behavior, 35 pp.S139S157.

Ng, ES et al. (2017) 'Millennials in Canada: Young Workers in a Challenging Labour Market' in E Parry \& J McCarthy (eds.) The Palgrave Handbook of Age Diversity and Work, Palgrave Macmillan, London, pp. 325-344.

Price, R et al. (2011) 'A Majority Experience: Young People's Encounters with the Labour Market' in R Price et al. (eds.), Young People and Work, Aldershot, Ashgate, pp. 1-17.

Stewart, JS et al. (2017) 'Managing Millennials: Embracing Generational Differences' Business Horizons, 60(1) pp. 45-54.

Twenge, JM et al. (2010) 'Generational Differences in Work Values: Leisure and Extrinsic Values Increasing, Social and Intrinsic Values Decreasing' Journal of Management, 36(5) pp.1117-1142. Twenge, JM (2014) Generation Me (Revised ed.), New York, Simon and Schuster.

Woodman, D (2016) 'The Sociology of Generations and Youth Studies' in A Furlong (ed.) Handbook of Youth and Young Adulthood (2nd ed.), London: Routledge, pp. 20-26.

Woodman, D \& Wyn, J (2015) Youth and Generation: Rethinking Change and Inequality in the Lives of Young People, London: Sage.

Wyn, J and Woodman, D (2006) 'Generations, Youth and Social Change in Australia' Journal of Youth Studies, 9(5), pp. 495 - 514. 
Woodman, D. (forthcoming) Continuity and Change in Attitudes to Job Security Across Two

Generations... Labour and Industry (author's post-review copy)

Wyn, J \& Woodman, D (2007) 'Researching Young People in a Context of Change: A reply to Roberts' Journal of Youth Studies, 10(3), pp. 495 - 514.

\section{Notes}

1 Myers is like Sears or Macy's in the USA and Marks and Spencer in the UK

2 The year range for Generation X categorisation is approximately the mid-1960s through to the end of the 1970s (there is some variation in the typologies). As noted earlier, Generation Y (also commonly known as the Millennials) where born around 1980 through to anywhere from the mid-1990s to the early 2000 s.

3 The interviews with the 2006 cohort have been led by the author, who also conducted many of them, with support from other team members. The records of the interviews with the 1991 cohort are incomplete the interviewer is no longer connected with the project; some of the interviews may have taken place in 1998 and some in 2000 and the interviews were also only partially transcribed (with further details recorded as interviewer notes). As such, the quality and extent of the excerpts and the demographic data available is less than for the 2006 cohort interviews but detailed enough to make a comparison. Relatedly, some of the excerpts from interviews with the 1991 cohort used here have appeared in an earlier Life Patterns working paper - Dwyer and colleagues (1999). Further details on the project are available here $<$ https://education.unimelb.edu.au/yrc/research/life-patterns $>$

4 The names used for the interview participants are pseudonyms. 